(2). $\begin{array}{r}2018 \text { Volume 24(2): 615-634 } \\ \text { doi:10.3846/20294913.2016.1213207 }\end{array}$

\title{
THIRD-PARTY LOGISTICS (3PLS) PROVIDER SELECTION VIA FUZZY AHP AND EDAS INTEGRATED MODEL
}

\author{
Fatih ECER \\ Department of Business Administrative, Faculty of Economics and Administrative Sciences, ANS \\ Campus, Afyon Kocatepe University, Afyonkarahisar 03030, Turkey
}

Received 20 November 2015; accepted 10 April 2016

\begin{abstract}
In the global competitive environment, companies not only improve the quality of service and increase the efficiency, they also decrease the cost by means of third-party logistics (3PLs). 3PLs, therefore, is an important strategy for companies desiring to gain a competitive advantage and 3PLs provider selection plays a critical role for the success of outsourcing. Nevertheless, the level of uncertainty in the selection process is relatively high and need to be carefully considered. Hence, in order to select a proper 3PLs provider, integration of the Fuzzy AHP and Evaluation based on Distance from Average Solution (EDAS) has offered a novel integrated model, in which Fuzzy AHP is used for calculating priority weights of each criteria and EDAS is employed to achieve the final ranking of 3PLs providers. Besides, in order to demonstrate the applicability of the proposed model, it is validated by a case study. Cost together with quality, and professionalism are found to be the most important factors for 3PLs provider selection. Consequently, the advantage of this model is that it is simple to apprehend and easy to apply. The use of the proposed model leads to the selection of suitable alternative successfully in other selection problems.
\end{abstract}

Keywords: 3PLs, Fuzzy AHP, EDAS, logistics outsourcing, provider selection.

JEL Classification: C44, D81, M11.

\section{Introduction}

In order to handle a company's logistics activities effectively and efficiently, it can outsource the function and buy the service (Yayla et al. 2015). The third-party logistics (3PLs), was launched in U.S. and Europe in 1980s. The 3PLs is the individualized service offered by an intermediary between the consigner and the consignee at a stated price within a stated period of time on the basis of modern information technology, such as timely delivery and combining orders, to realize quicker reaction to the clients' needs and more profit with less cost (Zhang, Y., Zhang, R. 2010). More specifically, a specialized 3PLs provider is an

Corresponding author Fatih Ecer

E-mail:fecer@aku.edu.tr 
outside company that performs some or all of a firm's logistics activities. Firms choose to specialize in performing functions associated with increasing returns. 3PLs provider is able to reduce clients' operational costs, transportation lead time, and support the provision of higher customer service level thus making its clients more competitive (Banomyong, Supatn 2011; Jarzemskis 2006). Additionally, the 3PLs providers can spread the risks by outsourcing to sub-contractors since investment in logistics assets usually needs large and lump sum costs, which involves financial risks (Vasiliauskas, Jakubauskas 2007). There is an increasing trend that manufacturing companies outsource their logistics activities to meet their increasing need for logistics services. According to a survey performed by Forrester Research, $78 \%$ of Fortune 500 companies have outsourced transportation services, $54 \%$ of them have outsourced their distribution services, and $46 \%$ of them have outsourced their manufacturing activities (Akman, Baynal 2014).

Logistics industry constitutes almost $10-15 \%$ of the total global GDP and is an integral portion of Turkey's economy. According to Logistics Performance Index (LPI) prepared by the World Bank, Turkey is ranked 30th with 3.50 points out of the 155 countries in the index. There are a large number of logistics provider firms in Turkey. These are newly founded small and medium sized firms with a transportation background. Rapidly growing trade with Turkey has created a promising perspective for the logistics industry and the trend is expected to continue (World Bank 2015; Akman, Baynal 2014).

Due to designing computational and mathematical techniques for supporting the subjective evaluation of evaluation factors by decision makers, multiple criteria decision making (MCDM) is attracted increasing attention (Mardani et al. 2015). As one of the most widely utilized MCDM techniques AHP is proposed by Saaty (1980) to solve complex MCDM problems involving qualitative decisions. On the other hand, EDAS method developed by Keshavarz Ghorabaee et al. (2015) is a relatively new MCDM method. The method utilizes an average solution for appraising the alternatives. The most significant characteristics of the EDAS method are its simplicity and lower computational process.

Rather often, 3PLs provider selection problem is examined using MCDM in that qualitative and quantitative criteria some of which can conflict each other need to be considered. In reality, crisp numbers may not always be adequate to present the decision making process, since human perception, judgment, intuition, and preference remain vague and difficult to measure. Fuzzy set theory (Zadeh 1965) is a way of addressing vague concepts and provides a means for representing uncertainty in order to handle the vagueness involved in the real situation (Ecer 2015; Chou, Cheng 2012; Chen, Wang 2009).

Fuzzy MCDM (FMCDM) has been developed with the help of fuzzy set theory. FMCDM methods may help resolve some difficulties frequently encountered in decision making. It mainly aims to reduce the effects of imprecision like human judgment and preferences while searching for the optimal decision. FMCDM is generally based on fuzziness of MCDM theories where it is a tool that aids decision makers to manage the uncertainty of their, sometimes subjective, judgments. When decision makers evaluate an exact judgment by crisp numbers rather than qualitative expressions, MCDM uses fuzzy evaluations and presents the appropriateness of alternatives against each other (Arslan, Aydin 2009). 
FMCDM can be categorized as a fuzzy multi objective decision making (FMODM) and fuzzy multi attribute decision making (FMADM) approach. The aim of FMADM is finite and implicit, while the aim of the FMODM approach is infinite and explicit (Mardani et al. 2015). FMCDM has an advantage of not complicating the problem due to neither the number of criteria nor the number of alternatives. Besides, the results are both realistic and satisfactory (Arslan, Aydın 2009). FMCDM methods have been studied extensively in the literature. Mardani et al. (2015) categorized the FMCDM studies into four parts: engineering, science, business, and technology. In their study, engineering is the field that has mostly used the FMCDM methods and approaches. Besides, 122 studies are applied FMCDM tools and applications in the field of management and business until 2014. From various studies, Balezentis et al. (2012) have applied Fuzzy VIKOR, Fuzzy TOPSIS, and Fuzzy ARAS for comparison of Lithuanian economic sectors on the basis of financial ratios. Cheng (2013) employed Fuzzy AHP for the selection of technology valuation methods for the development of new materials. Kahraman et al. (2014) used Fuzzy AHP for the selection of health research investment alternatives. Safaei Ghadikolaei et al. (2014) proposed Fuzzy AHP, Fuzzy VIKOR, Fuzzy ARAS, and Fuzzy COPRAS for financial performance evaluation of Iranian companies. Ecer (2015) implemented of Fuzzy AHP and COPRAS-G for evaluation of internet banking branches. Balin and Baraçli (2015) have employed Fuzzy AHP based upon type-2 fuzzy sets and interval type-2 TOPSIS for determining the best renewable energy alternatives for Turkey.

Accordingly, the ultimate purpose of this study is to present an integrated FMCDM model integrated Fuzzy AHP and EDAS. To do this, the Fuzzy AHP is used to determine the priority weights of selection criteria since it is based on pairwise comparisons and allows the utilization of linguistic variables. Then, the EDAS method is utilized ranking of 3PLs. The second objective of this study is building an effective decision tool to evaluate performances of 3PLs providers and find out the best provider. To the best of our knowledge, no study has been done for solving 3PLs provider selection problems, by using an integrate Fuzzy AHP and EDAS method. Moreover, in order to verify the applicability of this integrated model, a case study of four 3PLs providers in Afyonkarahisar (Turkey) is offered. The contributions of this study in extant literature are twofold. First, to date, there is no research to our knowledge which integrates Fuzzy AHP and EDAS method. Second, till date, EDAS has not been used for 3PLs provider evaluation and selection. Furthermore, the findings of this paper can help 3PLs providers for a clear picture of their situation and then prioritize the strategies for improvement. Additionally, this study will be a valuable contribution to achieving desired 3PLs quality levels. Hence, this integrated model represents an effective tool for evaluating 3PLs providers.

The study is outlined in the following manner: Section 2 presents 3PLs provider selection process and includes a detailed literature survey integrated methodologies related to selection of 3PLs. The Fuzzy AHP and EDAS methods are explained in detail in Section 3. A case study for the proposed integrated model is performed for a marble company in Section 4. In the last section, conclusion, limitation, and managerial implications of the study are discussed. 


\section{3PLs provider selection}

In the competitive market environment, it is necessary for a firm to be competitive with working in close cooperation with partners. The 3PLs has been widely promoted by the phenomenon of outsourcing, on which companies increasingly rely. Reducing costs, improving performance, focusing on firms' core business, and building virtual enterprises via strategic alliances can be thought as the main benefits of 3PLs (Aguezzoul 2014).

"Logistics outsourcing" or "outsourcing of logistics" synonymous terms can be considered instead of 3PLs in literature. Over the last three decades, most studies conducted on 3PLs provider selection. During this period, there are five streams of literature that relate to the 3PLs provider selection: MCDM, statistical methods, artificial intelligence, mathematical programming, and integrated methods. Among them, integrated methods are utilized to identify the most important evaluation criteria and to select the best 3PLs provider.

For example, Lehmusvaara et al. (1999) used an integrated AHP and mixed integer programming (MIP) model. Their model takes into account three main criteria (customer service, pricing and rates, strategic compatibility) and their nine sub-criteria. For the airline selection, Degraeve et al. (2004) proposed a mixed model that integrates MIP and total cost of ownership (TCO). As per Thakkar et al. (2005), they used a model integrating interpretive structural model (ISM) and analytical network process (ANP) for a appropriate 3PLs provider selection. In this sense, 15 criteria are considered: trustworthiness, trained logistics personnel, attitude toward entering into along-term contract, geographical coverage, necessary certifications, readiness, experience, flexibility, readiness to share experiences, attitude toward open-book accounting, attitude toward working under a computerized system, financial background, availability of computer network, margins, and readiness to utilize hygienic practices. Chow et al. (2005) suggested an integrated model using data mining and Case-Based Reasoning (CBR) to measure 3PLs provider performance. To do this, the evaluating criteria considered are related to customer service, real time information, reporting delivery accuracy, price, communication, stock status, and stock spacing. Işıklar et al. (2007) suggested a mixed system combining CBR and multi-objective programming (MOP) methods in fuzzy environment. As to this system, 3PLs provider performance is calculated by 11 criteria, namely: cost, developing a strong relationship, performance, quality, similar size, successful track record, comparable culture, financial stability, similar values and goals, information technology, and services. Almeida (2007) proposed a model for 3PLs provider selection combining utility function and ELECTRE method. Whilst the utility function is utilized to evaluate the performance factors (delivery time, cost, and dependability), ELECTRE method ranks the 3PLs providers. Büyüközkan et al. (2008) proposed a multicriteria model for 3PLs provider selection in Turkey based on Fuzzy AHP and Fuzzy TOPSIS. The Fuzzy AHP is introduced to determine the relative weights of evaluation criteria while Fuzzy TOPSIS determines the final ranking of 3PLs provider. For such, 10 evaluation criteria are considered which are: a fit to develop a sustainable relationship, market knowledge, similar values-goals, managerial experience, financial stability, successful track record, comparable culture, technical expertise, performance, and similar size. As per Efendigil et al. (2008), an integrated model integrating Fuzzy AHP and artificial neural network (ANN) models to select a suitable 3PLs provider. The 12 performance criteria 
considered in their model are: total order cycle time, integration level index, service quality level, confirmed fill rate, environmental expenditures, unit operation cost, system flexibility index, on time delivery ratio, increment in market share, capacity usage ratio, research and development ratio, and customer satisfaction index. Choy et al. (2008) proposed an integrated CBR and nonlinear programming (NLP) techniques for selecting 3PLs provider. They utilized 6 performance criteria (services, flexibility, quality, cost, delivery, and relationship) in their study. Kannan et al. (2009) used an integrated ISM and TOPSIS model for the evaluation and selection of 3PLs providers under fuzzy environment in India. They took into consideration 7 criteria (technical and engineering capability, delivery, rejection rate, cost, willingness and attitude, insufficient to meet business requirement, and quality) in their model. Liou and Chuang (2010) developed a model that combined DEMATEL, ANP, and VIKOR methods. After constructing the interrelationship between criteria by DEMATEL and weighting the criteria by ANP, VIKOR was utilized to determine the final ranking of 3PLs provider. For this, 12 criteria are used: control, information security, flexibility in billing, information sharing, on time rate, cost savings, relationship, labor union, flexibility, loss of management, knowledge and skills, and client's satisfaction. Zhang et al. (2012) suggested a model combining information granulation entropy approach, K-means clustering, and TOPSIS method for selecting 3PLs provider. Firstly, information granulation entropy was handled for weighting the criteria. Then, TOPSIS was used to derive the primacies of 3PLs provider. Their model takes into account 5 main criteria: operational capabilities, financial performance, improvement and compatibility, client relationship, and enterprise culture. Falsini et al. (2012) suggested an integrated method that combines AHP, data envelopment analysis (DEA), and linear programming (LP) to evaluate and select the best 3PLs provider in Italy. The 7 criteria considered are: equipment, speed of service, operators' safety, flexibility, reliability of quality, cost, and environmental safeguard. Kabir (2012) suggested an integrated model using Fuzzy AHP and TOPSIS. He determined compatibility, financial stability, flexibility, operational performance, quality management, and reputation as criteria. Ho et al. (2012) proposed an integrated quality function deployment (QFD) and Fuzzy AHP for 3PLs provider selection in China. They used 6 criteria which are delivery, risk, technology, quality, cost, and flexibility. Perçin and Min (2013) suggested a model that combines QFD, fuzzy linear regression (FLR) and MOP to select proper 3PLs auto part provider in Turkey. For this, 5 criteria are used: service quality, reputation, flexibility, cost, and timeless. Hsu et al. (2013) suggested a model combining DEMATEL and ANP. For this, 12 criteria are used: labor union, control, information sharing, client's satisfaction, on time rate, cost savings, flexibility, loss of management, relationship, knowledge and skills, flexibility in billing, and information security. In Akman and Baynal's (2014) study evaluation criteria were determined as on time delivery, price, product availability, reliability, firm's background, reputation, knowledge sharing, and flexibility. They used a model integrating Fuzzy AHP and TOPSIS techniques. Yayla et al. (2015) suggested an integrated model that combined AHP, Fuzzy AHP, and Fuzzy TOPSIS for 3PLs provider evaluation. They used 3 main criteria and their 11 sub-criteria which are: developing sustainable relationship (transportation cost, financial health, provider reputation, and similar values), service quality (delivery reliability, response in emergency, on-time delivery, and quality of dispatch personnel), and continuous improvement (technological sophistication, 
optimisation capabilities, and firm's infrastructure). Sharma and Kumar (2015) developed an integrated approach, combining QFD and Taguchi loss function (TLF) to select optimal 3PLs provider. They identified 5 criteria: costs, timeliness (including on-time order fulfillment and delivery), service quality (reliability scope of services, personalized service), flexibility (special and emergency need related to product types or packaging), and reputation (brand recognition). Finally, Alkhatib et al. (2015) proposed an integrated 3PLs approach to evaluate and select the best provider. They combine a Fuzzy DEMATEL and Fuzzy TOPSIS methods. Their model considered five sub-criteria and grouped into two main criteria. For such, main criteria and their sub-criteria are considered which are: tangible logistics resources and capacities (physical resources and capacities, technological resources and capacities) and intangible logistics resources and capacities (human resources and capacities, relational resources and capacities, and structural resources and capacities).

\section{Methodology}

This study integrates a Fuzzy AHP with an EDAS method to establish a new integrated FMCDM model to assess 3PLs provider. To achieve this, the Fuzzy AHP method is utilized to handle the vague information from expert judgments to determine the priority weights of the factors. Then, the EDAS method is employed to present preference of the 3PLs provider with regard to each factor and calculate the weighted priorities of the 3PLs. The details of the methods are explained in the following subsections.

\subsection{The Fuzzy AHP method}

As one of the most utilized MCDM methods, the AHP method was developed by Saaty (1980). AHP has many advantages. For example, AHP provides a measure of consistency in decision makers' judgments or preferences. AHP also allows decision makers to start from pairwise comparisons that are simple enough to work with and often are preferred by the decision makers (Gao, Hailu 2013; Ecer 2014). Fuzzy AHP is used for obtaining more decisive judgments by prioritizing the selection criteria and weighting them in the presence of vagueness in the problems (Hashemkhani Zolfani et al. 2012). The outlines of fuzzy sets and extent analysis method for Fuzzy AHP are given below (Hsieh et al. 2005; Aghdaie et al. 2013; Ecer 2015).

Fuzzy numbers are seen as a fuzzy subset of real numbers and a fuzzy number $A$ on $\mathfrak{R}$ is expressed as $A=\left\{\left(x, \mu_{A}(x)\right), x \in \mathfrak{R}\right\}$, where $\mu_{A}(x)$ is a membership function and $\mu_{A}(x): \mathfrak{R} \rightarrow[0,1]$.

A triangular fuzzy number (TFN) is equal to

$$
\mu_{A}(x)= \begin{cases}0 & , x<p \\ (x-p) /(r-p) & , p \leq x \leq r \\ (s-x) /(s-r) & , r \leq x \leq s \\ 0 & , x>s\end{cases}
$$

where $p$ and $s$ indicate lower and upper bounds of $A$, respectively, and $r$ for the cen- 
ter value. The following is the main operational rules of two TFNs $M_{1}=\left(p_{1}, r_{1}, s_{1}\right)$ and $M_{2}=\left(p_{2}, r_{2}, s_{2}\right)$.

$$
\begin{gathered}
\left(p_{1}, r_{1}, s_{1}\right) \oplus\left(p_{2}, r_{2}, s_{2}\right)=\left(p_{1}+p_{2}, r_{1}+r_{2}, s_{1}+s_{2}\right) \text { (Addition); } \\
\left(p_{1}, r_{1}, s_{1}\right) \otimes\left(p_{2}, r_{2}, s_{2}\right)=\left(p_{1} p_{2}, r_{1} r_{2}, s_{1} s_{2}\right) \text { (Multiplication); } \\
\left(p_{1}, r_{1}, s_{1}\right)^{-1} \approx\left(1 / s_{1}, 1 / r_{1}, 1 / p_{1}\right) \text { (Reciprocal) }
\end{gathered}
$$

In order to transform the linguistic variables into fuzzy numbers, Table 1 is utilized.

Table 1. The fuzzy conversion

\begin{tabular}{lc}
\hline \multicolumn{1}{c}{ Linguistic variable } & Fuzzy number $(p, r, s)$ \\
\hline Just equal & $(1,1,1)$ \\
\hline Equal importance & $(1,1,3)$ \\
\hline Weak importance of one over another & $(1,3,5)$ \\
\hline Essential or strong importance & $(5,5,7)$ \\
\hline Very strong importance & $(7,9,9)$ \\
\hline Extremely preferred & \\
\hline If factor $i$ has one of the above numbers assigned to it when compared to factor $j$, & \\
then $j$ has the reciprocal value when compared with $i: M_{1}^{-1} \approx\left(\frac{1}{s_{1}}, \frac{1}{r_{1}}, \frac{1}{p_{1}}\right)$
\end{tabular}

Let $X=\left\{x_{1}, x_{2}, \ldots, x_{n}\right\}$ be an object set, and $G=\left\{g_{1}, g_{2}, \ldots, g_{m}\right\}$ be a goal set. According to the Chang's extent analysis (1992), each object is taken and extent analysis for each goal is performed, respectively. Hence, $m$ extent analysis values for each object can be obtained, with the following signs:

$$
M_{g_{i}}^{1}, M_{g_{i}}^{2}, \ldots, M_{g_{i}}^{m}, i=1,2, \ldots, n,
$$

where all the $M_{g_{i}}^{j}(j=1,2, \ldots, m)$ are TFNs. The steps of extent analysis can be given as in the following:

Step 1. The value of fuzzy synthetic extent as to the ith object is defined as:

$$
S_{i}=\sum_{j=1}^{m} M_{g_{i}}^{j} \otimes\left[\sum_{i=1}^{n} \sum_{j=1}^{m} M_{g_{i}}^{j}\right]^{-1}
$$

In order to obtain $\sum_{j=i}^{m} M_{g_{i}}^{j}$, apply the fuzzy addition operation of $m$ extent analysis values for a particular matrix such that:

$$
\sum_{j=1}^{m} M_{g_{i}}^{j}=\left(\sum_{j=1}^{m} p_{j}, \sum_{j=1}^{m} r_{j}, \sum_{j=1}^{m} s_{j}\right)
$$

and to obtain $\left[\sum_{i=1}^{n} \sum_{j=1}^{m} M_{g_{i}}^{j}\right]^{-1}$ apply the fuzzy addition operation of $M_{g_{i}}^{j}(j=1,2, \ldots, m)$ 
values such that

$$
\sum_{i=1}^{n} \sum_{j=1}^{m} M_{g_{i}}^{j}=\left(\sum_{i=1}^{n} p_{i}, \sum_{i=1}^{n} r_{i}, \sum_{i=1}^{n} s_{i}\right)
$$

and then calculate the inverse of the vector in Eq. (8) such that

$$
\left[\sum_{i=1}^{n} \sum_{j=1}^{m} M_{g_{i}}^{j}\right]^{-1}=\left(1 / \sum_{i=1}^{n} s_{i}, 1 / \sum_{i=1}^{n} r_{i}, 1 / \sum_{i=1}^{n} p_{i}\right) .
$$

Step 2. The degree of possibility of $M_{2}=\left(p_{2}, r_{2}, s_{2}\right) \geq M_{1}=\left(p_{1}, r_{1}, s_{1}\right)$ is defined as

$$
V\left(M_{2} \geq M_{1}\right)=\sup _{y \geq x}\left[\min \left(\mu_{M_{1}}(x), \mu_{M_{2}}(y)\right]\right.
$$

and can be equivalently expressed as follows:

$$
V\left(M_{2} \geq M_{1}\right)=h g t\left(M_{1} \cap M_{2}\right)=\mu_{M_{2}}(d)=\left\{\begin{array}{l}
1, \text { if }\left(r_{2} \geq r_{1}\right), \\
0, \text { if }\left(p_{1} \geq s_{2}\right), \\
\left(p_{1}-s_{2}\right) /\left[\left(r_{2}-s_{2}\right)-\left(r_{1}-p_{1}\right)\right], \text { otherwise, }
\end{array}\right.
$$

Figure 1 illustrates Eq. (11) where $d$ is the ordinate of the highest intersection point $D$ between $\mu_{M_{1}}(x)$ and $\mu_{M_{2}}(x)$. In order to compare $M_{1}$ and $M_{2}$ it is needed both the values of $V\left(M_{1} \geq M_{2}\right)$ and $V\left(M_{2} \geq M_{1}\right)$.

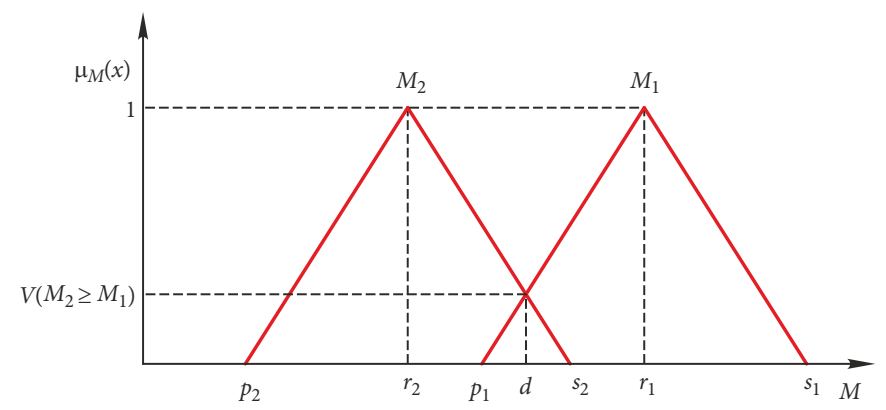

Fig. 1. The intersection between $M_{1}$ and $M_{2}$ (Source: Hsieh et al. 2005)

Step 3. The degree possibility for a convex fuzzy number to be greater than $k$ convex fuzzy numbers $M_{i}(i=1,2, \ldots, k)$ can be defined by

$$
\begin{aligned}
& V\left(M \geq M_{1}, M_{2}, \ldots, M_{k}\right)=V\left[\left(M \geq M_{1}\right) \cap\left(M \geq M_{2}\right) \cap \ldots \cap\left(M \geq M_{k}\right)\right] \\
& =\min V\left(M \geq M_{i}\right), \quad i=1,2, \ldots, k .
\end{aligned}
$$

Assume that

$$
d^{\prime}\left(A_{1}\right)=\min V\left(S_{i} \geq S_{k}\right)
$$


for $k=1,2, \ldots, n ; k \neq i$. Then the weight vector is given by

$$
W^{\prime}=\left(d^{\prime}\left(A_{1}\right), d^{\prime}\left(A_{2}\right), \ldots, d^{\prime}\left(A_{n}\right)\right)^{T},
$$

where $A_{i}(i=1,2, \ldots, n)$ are $n$ elements.

Step 4. Via normalization, the normalized weight vectors are:

$$
W=\left(d\left(A_{1}\right), d\left(A_{2}\right), \ldots, d\left(A_{n}\right)\right)^{T},
$$

where $W$ is a non-fuzzy number.

\subsection{The EDAS method}

The EDAS method was developed by Keshavarz Ghorabaee et al. (2015). The method is very useful when it has been some conflicting criteria. According to the EDAS method, the best alternative is related to the distance from average solution $(A V)$. It is need to calculate two measures dealing with the desirability of the alternatives: the positive distance from average (PDA) and the negative distance from average (NDA). As $n$ and $m$ represent number of alternative and number of criterion, respectively, the steps of this method are presented as follows (Keshavarz Ghorabaee et al. 2015):

Step 1. Construct the decision-making matrix $(X)$

$$
X=\left[X_{i j}\right]=\left[\begin{array}{cccc}
X_{11} & X_{12} & \cdots & X_{1 m} \\
X_{21} & X_{22} & \cdots & X_{2 m} \\
\vdots & \vdots & \ddots & \vdots \\
X_{n 1} & X_{n 2} & \cdots & X_{n n}
\end{array}\right],
$$

where $X_{i j}$ denotes the performance value of $i$ th alternative on $j$ th criterion.

Step 2. Determine the average solution according to all criteria, shown as follows:

$$
A V=\left[A V_{j}\right]_{1 x m},
$$

where,

$$
A V_{j}=\frac{\sum_{i=1}^{n} X_{i j}}{n} .
$$

Step 3. Calculate $P D A$ and NDA matrixes according to the type of criteria (benefit and cost), shown as follows:

$$
\begin{aligned}
P D A & =\left[P D A_{i j}\right]_{n x m} ; \\
N D A & =\left[N D A_{i j}\right]_{n x m},
\end{aligned}
$$

if $j$ th criterion is beneficial,

$$
P D A_{i j}=\frac{\max \left(0,\left(X_{i j}-A V_{j}\right)\right)}{A V_{j}} ;
$$




$$
N D A_{i j}=\frac{\max \left(0,\left(A V_{j}-X_{i j}\right)\right)}{A V_{j}},
$$

if $j$ th criterion is cost (non-beneficial),

$$
\begin{aligned}
P D A_{i j} & =\frac{\max \left(0,\left(A V_{j}-X_{i j}\right)\right)}{A V_{j}} ; \\
N D A_{i j} & =\frac{\max \left(0,\left(X_{i j}-A V_{j}\right)\right)}{A V_{j}},
\end{aligned}
$$

where $P D A_{i j}$ and $N D A_{i j}$ denote the positive and negative distance of $i$ th alternative from average solution in terms of $j$ th criterion, respectively.

Step 4. Determine the weighted sum of $P D A$ and NDA for all alternatives, shown as follows:

$$
\begin{gathered}
S P_{i}=\sum_{j=1}^{m} w_{j} P D A_{i j} ; \\
S N_{i}=\sum_{j=1}^{m} w_{j} N D A_{i j},
\end{gathered}
$$

where $w_{j}$ is the priority weight of $j$ th criterion.

Step 5. Normalize the values of $S P$ and $S N$ for all alternatives, shown as follows:

$$
\begin{gathered}
N S P_{i}=\frac{S P_{i}}{\max _{i}\left(S P_{i}\right)} ; \\
N S N_{i}=1-\frac{S N_{i}}{\max _{i}\left(S N_{i}\right)} .
\end{gathered}
$$

Step 6. Calculate the appraisal score $(A S)$ for all alternatives, shown as follows:

$$
A S_{i}=\frac{N S P_{i}+N S N_{i}}{2}
$$

where $0 \leq A S_{i} \leq 1$.

Step 7. Rank the alternatives according to the decreasing values of $A S$. The alternative with the highest $A S$ is the best choice among the candidate alternatives.

\section{A case study in a marble company}

\subsection{Determination of priority weights using the Fuzzy AHP}

The goal is to select a suitable 3PLs provider among the alternatives. Hence, a decision making team including four experts is constructed to determine and assess the selection criteria. The title of the survey respondents is distribution manager, logistics manager, materials manager, and logistics director. Based on the extensive literature survey and a series of discussions, the decision making team develops various 3PLs provider selection 
criteria. For such, 11 criteria are considered which are: cost, relationship, services, quality, information system, flexibility, delivery, professionalism, financial position, location, and reputation. In this context, in Table 2, evaluation criteria are given with their definitions.

Table 2. 3PLs provider selection criteria

\begin{tabular}{|c|c|c|}
\hline Criteria & Definition & Goal \\
\hline Cost (CO) & $\begin{array}{l}\text { It means the total cost of 3PLs (Jharkharia, Shankar 2007). Price, } \\
\text { cost reduction, low cost distribution, expected leasing cost, } \\
\text { operation cost, warehousing cost, and cost savings are among its } \\
\text { attributes (Aguezzoul 2014). }\end{array}$ & Min \\
\hline Relationship (RS) & $\begin{array}{l}\text { Compatibility, truth, reliability, dependence, alliance, and } \\
\text { reciprocity are among its attributes (Aguezzoul 2014; Hsu et al. } \\
\text { 2013). }\end{array}$ & Max \\
\hline Services (SR) & $\begin{array}{l}\text { Breadth of services, specialization of services, diversity of } \\
\text { available services, customer services, and value-added services } \\
\text { (Aguezzoul 2014). It is critical to select a 3PLs provider, who } \\
\text { is able to provide flexible, tailor-made solutions to meet their } \\
\text { changing needs (Ho et al. 2012). Adding services criteria to } \\
\text { the 3PLs provider selection framework improves the selection } \\
\text { quality. }\end{array}$ & $\operatorname{Max}$ \\
\hline Quality (QA) & $\begin{array}{l}\text { A clearly spelled-out quality program or the ISO } 9001 \text { standards } \\
\text { certification surely characterize an ideal logistics partner } \\
\text { (Bottani, Rizzi 2006). Commitment to continuous improvement, } \\
\text { SQAS/ISO standards environment issues, and risk management } \\
\text { are among its attributes (Aguezzoul 2014). }\end{array}$ & Max \\
\hline Information System (IS) & $\begin{array}{l}\text { Information system usually contains both software and hardware } \\
\text { (Bottani, Rizzi 2006). EDI, ERP, technology capabilities, } \\
\text { technical capability, information accessibility, information } \\
\text { security, availability of computer network, and informatization } \\
\text { level are among its attributes (Aguezzoul 2014). }\end{array}$ & Max \\
\hline Flexibility (FL) & $\begin{array}{l}\text { Ability to adapt to changing clients requirements and } \\
\text { circumstances (Aguezzoul 2014). The 3PLs provider has an } \\
\text { adequate flexibility to respond to changes (Bottani, Rizzi 2006). }\end{array}$ & $\operatorname{Max}$ \\
\hline Delivery (DE) & $\begin{array}{l}\text { Time, on-time performance, on time shipment and deliveries, } \\
\text { delivery speed, accuracy of transit/delivery time, shipment } \\
\text { delivery, and on-time delivery rate (Aguezzoul 2014). }\end{array}$ & Max \\
\hline Professionalism (PF) & $\begin{array}{l}\text { It is related to attributes such as expertise, competence, and } \\
\text { experience (Aguezzoul 2014). }\end{array}$ & $\operatorname{Max}$ \\
\hline Financial Position (FP) & $\begin{array}{l}\text { It refers to continuity of service and regular upgrading of the } \\
\text { equipments and services used in logistics operations (Aguezzoul } \\
\text { 2014). Financial strength can be a good indicator of the } \\
\text { supplier's long-term stability (Yayla et al. 2015). }\end{array}$ & Max \\
\hline Location (LO) & $\begin{array}{l}\text { Shipment destinations, international scope, distribution } \\
\text { coverage, market coverage, geographical specialization and } \\
\text { coverage, and distance are among its attributes (Aguezzoul } \\
\text { 2014). }\end{array}$ & Max \\
\hline Reputation (RP) & $\begin{array}{l}\text { Reputation is the subjective "feel" of the provider, derived from } \\
\text { the industry for the 3PLs provider. This is more relevant in the } \\
\text { initial screening of 3PLs (Aguezzoul 2014; Yayla et al. 2015). }\end{array}$ & Max \\
\hline
\end{tabular}


In order to demonstrate the applicability of the proposed Fuzzy AHP and EDAS integrated model in a 3PLs provider selection problem, it is applied on medium-sized marble company (called "XYZ" hereafter for confidentiality) that operates in Afyonkarahisar (Turkey). This company owns two marble quarries in Afyonkarahisar and produces annually approximately $10,000 \mathrm{~m}^{3}$ marble blocks. The XYZ marble company exports its products to Europe, Asia, Australia, and Middle East countries since 1994. Furthermore, XYZ outsources its outbound logistics by means of four providers. Of these four providers, $A$ is an administration-based company which focuses predominantly on logistics administration services. The provider B is an asset-based company which owns specific assets through which logistics services are offered. However, $\mathrm{C}$ is a non-assets based company which forms a contract with other firms to provide services instead of using the major part of its assets. Finally, the provider D is management-based company which does not own assets but tend to supply management consulting services.

In order to collect the responses of decision making team members, Delphi technique (see Ecer 2015) is conducted. Hence, pairwise comparison matrix of 11 criteria is constructed to get their priority weight over other. The fuzzy values of paired comparison are converted to crisp numbers by the Chang's extent analysis. Table 3 shows the fuzzy evaluation of the factors. Furthermore, the obtained priority weight $(w)$ vector of factors is figured out in the last column of Table 3. Hence, cost has the highest priority weight $(w)$ of 0.248 , followed by quality (0.185), and professionalism (0.107). Additionally, flexibility, reputation, relationship, and services are the top 3PLs provider selection criteria. Delivery, however, has the lowest priority weight of 0.010 .

Finally, the criteria hierarchy is illustrated in Figure 2. The priority weights will be utilized in EDAS method the following subsection.

Table 3. Fuzzy evaluation of the criteria

\begin{tabular}{|c|c|c|c|c|c|c|c|c|c|c|c|c|}
\hline \multirow[b]{3}{*}{$\mathrm{CO}$} & \multicolumn{12}{|c|}{ 3PLs provider selection criteria } \\
\hline & $\mathrm{CO}$ & $R S$ & $S R$ & $Q A$ & $I S$ & $F L$ & $D E$ & $P F$ & $F P$ & $L O$ & $R P$ & $w$ \\
\hline & $(1,1,1)$ & $(7,9,9)$ & $(1,3,5)$ & $(1,1,3)$ & $(3,5,7)$ & $(1,1,3)$ & $(3,5,7)$ & $(7,9,9)$ & $(1,3,5)$ & $(5,7,9)$ & $(7,9,9)$ & 0.248 \\
\hline$R S$ & $(0.11,0.11,0.14)$ & $(1,1,1)$ & $(0.2,0.33,1)$ & $(0.11,0.14,0.2)$ & $(0.33,1,1)$ & $(0.2,0.33,1)$ & $(0.33,1,1)$ & $(1,1,1)$ & $(0.33,1,1)$ & $(0.33,1,1)$ & $(1,1,1)$ & 0.097 \\
\hline$S R$ & $(0.33,0.33,1)$ & $(1,3,5)$ & $(1,1,1)$ & $(0.33,1,1)$ & $(1,1,3)$ & $(1,1,1)$ & $(1,1,3)$ & $(1,3,5)$ & $(1,1,1)$ & $(1,1,3)$ & $(1,1,3)$ & 0.067 \\
\hline$Q A$ & $(0.33,1,1)$ & $(5,7,9)$ & $(1,1,3)$ & $(1,1,1)$ & $(3,5,7)$ & $(1,1,3)$ & $(1,3,5)$ & $(1,3,5)$ & $(1,1,3)$ & $(3,5,7)$ & $(5,7,9)$ & 0.185 \\
\hline IS & $(0.14,0.20,0.33)$ & $(1,1,3)$ & $(0.33,1,1)$ & $(0.14,0.2,0.33)$ & $(1,1,1)$ & $(0.33,1,1)$ & $(1,1,1)$ & $(1,1,3)$ & $(0.33,1,1)$ & $(1,1,1)$ & $(1,1,1)$ & 0.040 \\
\hline$F L$ & $(0.33,1,1)$ & $(1,3,5)$ & $(1,1,1)$ & $(0.33,1,1)$ & $(1,1,3)$ & $(1,1,1)$ & $(1,1,3)$ & $(1,3,5)$ & $(1,1,3)$ & $(1,3,5)$ & $(1,3,5)$ & 0.101 \\
\hline$D E$ & $(0.14,0.20,0.33)$ & $(1,1,3)$ & $(0.33,1,1)$ & $(0.2,0.33,1)$ & $(1,1,1)$ & $(0.33,1,1)$ & $(1,1,1)$ & $(1,1,3)$ & $(1,1,1)$ & $(1,1,3)$ & $(1,1,3)$ & 0.010 \\
\hline$P F$ & $(0.11,0.11,0.14)$ & $(1,1,1)$ & $(0.2,0.33,1)$ & $(0.2,0.33,1)$ & $(0.33,1,1)$ & $(0.2,0.33,1)$ & $(0.33,1,1)$ & $(1,1,1)$ & $(0.33,1,1)$ & $(1,1,1)$ & $(1,1,1)$ & 0.107 \\
\hline$F P$ & $(0.20,0.33,1)$ & $(1,1,3)$ & $(1,1,19$ & $80.33,1,1)$ & $(1,1,3)$ & $(0.33,1,1)$ & $(1,1,1)$ & $(1,1,3)$ & $(1,1,1)$ & $(1,1,3)$ & $(1,1,3)$ & 0.029 \\
\hline$L O$ & $(0.11,0.14,0.20)$ & $(1,1,3)$ & $(0.33,1,1)$ & $(0.14,0.2,0.33)$ & $(1,1,1)$ & $(0.2,0.33,1)$ & $(0.33,1,1)$ & $(1,1,1)$ & $(0.33,1,1)$ & $(1,1,1)$ & $(1,1,1)$ & 0.016 \\
\hline$R P$ & $(0.11,0.11,0.14)$ & $(1,1,1)$ & $(0.33,1,1)$ & $(0.11,0.14,0.2)$ & $(1,1,1)$ & $(0.2,0.33,1)$ & $(0.33,1,1)$ & $(1,1,1)$ & $(0.33,1,1)$ & $(1,1,1)$ & $(1,1,1)$ & 0.101 \\
\hline
\end{tabular}




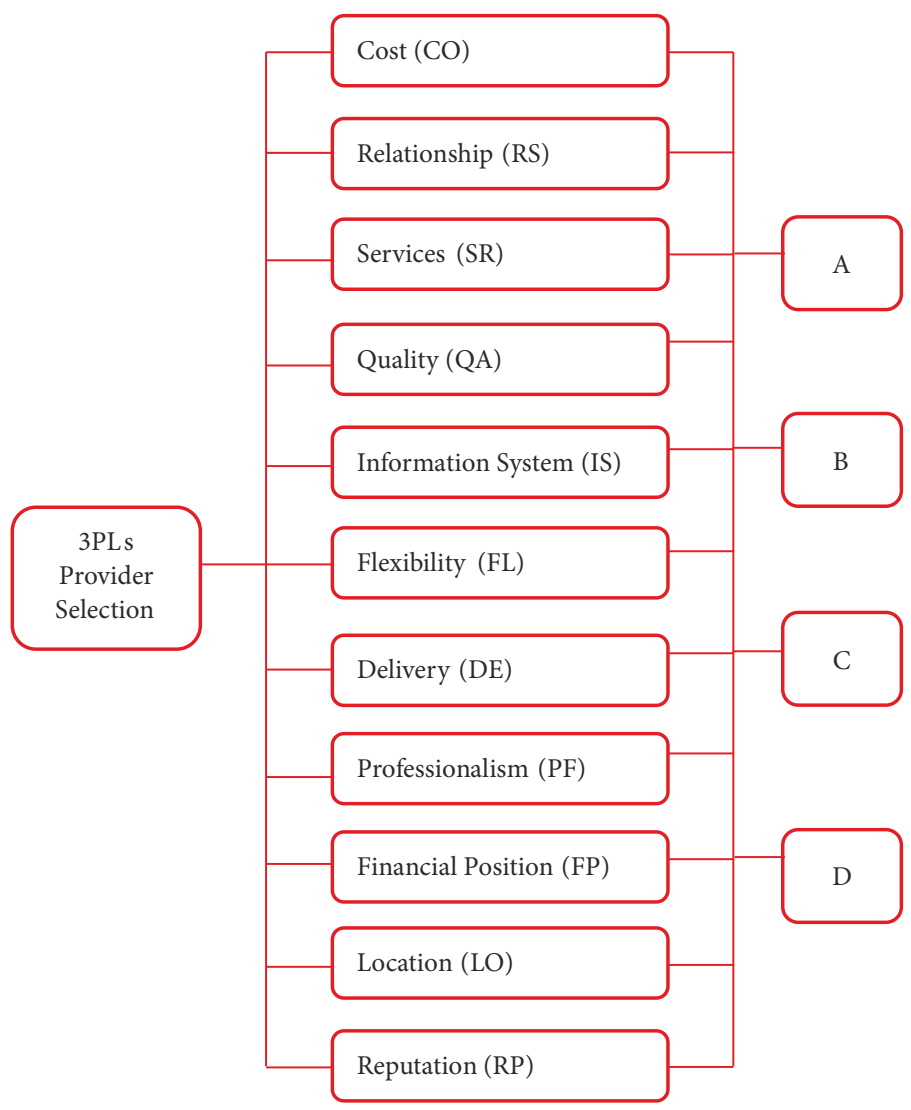

Fig. 2. The hierarchy for 3PLs provider selection

\subsection{Evaluation of 3PLs providers using the EDAS}

At this stage, the decision making team evaluates each 3PLs provider as to each criterion and then decision making matrix (Table 4) develops. All criteria are maximizing criteria with the exception of "cost" which is a minimizing criterion. The priority weights are determined through the Fuzzy AHP in previous sub-section.

Table 4. Decision making team evaluation of 3PLs providers

\begin{tabular}{|c|c|c|c|c|c|c|c|c|c|c|c|c|}
\hline & & \multicolumn{11}{|c|}{ 3PLs provider selection criteria } \\
\hline & & $\mathrm{CO}$ & $R S$ & $S R$ & $Q A$ & IS & $F L$ & $D E$ & $P F$ & $F P$ & $L O$ & $R P$ \\
\hline \multirow{4}{*}{$\begin{array}{l}\text { Alternative } \\
\text { 3PLs } \\
\text { providers }\end{array}$} & A & 6 & 6 & 8 & 7 & 6 & 4 & 7 & 6 & 9 & 4 & 4 \\
\hline & $\mathrm{B}$ & 7 & 4 & 5 & 9 & 4 & 8 & 5 & 6 & 4 & 5 & 10 \\
\hline & C & 6 & 3 & 4 & 2 & 8 & 6 & 4 & 5 & 7 & 9 & 4 \\
\hline & $\mathrm{D}$ & 6 & 10 & 8 & 7 & 6 & 9 & 9 & 8 & 5 & 10 & 6 \\
\hline
\end{tabular}


The results of steps 3 to 7 of the EDAS method are shown in Table 5. In this table, the values of PDA, NDA, SP, SN, NSP, NSN, and AS can be seen in terms of each 3PLs provider. It can be classified the 3 PLs providers as to values of appraisal scores $(A S)$ in Table 5. Consequently, the results show that the best 3PLs provider is $B$ with an $A S$ of 0.765 . On the basis of results obtained in Table 5, the provider $D$ with an AS of 0.699 is the second ranking 3PLs provider (with 1.000 as the desired level). The provider $A$ with an AS of 0.545 is the third ranking 3PLs provider. However, the provider $C$ with an $A S$ of 0.149 has the worst 3PLs provider.

Table 5. The evaluation of the appraisal score

\begin{tabular}{|c|c|c|c|c|}
\hline & \multicolumn{4}{|c|}{ Alternative 3PLs providers } \\
\hline & A & $\mathrm{B}$ & $\mathrm{C}$ & $\mathrm{D}$ \\
\hline$P D A_{i 1}$ & 0.057 & 0.000 & 0.000 & 0.214 \\
\hline$P D A_{i 2}$ & 0.000 & 0.000 & 0.000 & 0.310 \\
\hline$P D A_{i 3}$ & 0.257 & 0.000 & 0.000 & 0.048 \\
\hline$P D A_{i 4}$ & 0.100 & 0.478 & 0.000 & 0.000 \\
\hline$P D A_{i 5}$ & 0.000 & 0.000 & 0.517 & 0.000 \\
\hline$P D A_{i 6}$ & 0.000 & 0.313 & 0.138 & 0.179 \\
\hline$P D A_{i 7}$ & 0.100 & 0.000 & 0.000 & 0.179 \\
\hline$P D A_{i 8}$ & 0.000 & 0.000 & 0.000 & 0.048 \\
\hline$P D A_{i 9}$ & 0.414 & 0.000 & 0.328 & 0.000 \\
\hline$P D A_{i 10}$ & 0.000 & 0.000 & 0.707 & 0.310 \\
\hline$P D A_{i 11}$ & 0.000 & 0.642 & 0.000 & 0.000 \\
\hline$N D A_{i 1}$ & 0.000 & 0.149 & 0.138 & 0.000 \\
\hline$N D A_{i 2}$ & 0.057 & 0.343 & 0.431 & 0.000 \\
\hline$N D A_{i 3}$ & 0.000 & 0.179 & 0.241 & 0.000 \\
\hline$N D A_{i 4}$ & 0.000 & 0.000 & 0.621 & 0.083 \\
\hline$N D A_{i 5}$ & 0.057 & 0.343 & 0.000 & 0.214 \\
\hline$N D A_{i 6}$ & 0.057 & 0.000 & 0.000 & 0.000 \\
\hline$N D A_{i 7}$ & 0.000 & 0.179 & 0.241 & 0.000 \\
\hline$N D A_{i 8}$ & 0.057 & 0.015 & 0.052 & 0.000 \\
\hline$N D A_{i 9}$ & 0.000 & 0.343 & 0.000 & 0.345 \\
\hline$N D A_{i 10}$ & 0.214 & 0.179 & 0.000 & 0.000 \\
\hline$N D A_{i 11}$ & 0.371 & 0.000 & 0.241 & 0.214 \\
\hline$S P_{i}$ & 0.063 & 0.184 & 0.055 & 0.116 \\
\hline$N S P_{i}$ & 0.342 & 1.000 & 0.298 & 0.630 \\
\hline$S N_{i}$ & 0.060 & 0.112 & 0.239 & 0.056 \\
\hline$N S N_{i}$ & 0.747 & 0.531 & 0.000 & 0.768 \\
\hline$A S_{i}$ & 0.545 & 0.765 & 0.149 & 0.699 \\
\hline
\end{tabular}


A sensitivity analysis is applied to show how the rank order of 3PLs providers behaves when the criteria weights are switched. To achieve this, the priority weights obtained from Fuzzy AHP is switched for two criteria whilst the others are constant. Namely, the priority weight of the cost (CO) is switched with relationship (RS), services (SR) and so on, sequentially, while the others are constant. Afterwards, the EDAS method is applied again to rank 3PLs providers. Thus, the proposed model's stability against priority weight changes is observed. Eleven mutual priority weight change is realized during this process. According to Gumus (2009), the ranking changes can be seen, and this helps people determining priorities and making simpler the evaluation process. Table 6 shows the cases that considered. Besides, all cases in Table 6 are analyzed and the results are illustrated in Figure 3.

Table 6. The results of sensitivity analysis

\begin{tabular}{|c|c|c|c|c|c|c|c|c|c|c|c|c|}
\hline \multirow[t]{2}{*}{ Cases } & \multirow[t]{2}{*}{ Variables } & \multicolumn{11}{|c|}{ 3PLs provider selection criteria } \\
\hline & & $\mathrm{CO}$ & $\mathrm{RS}$ & SR & QA & IS & FL & $\mathrm{DE}$ & $\mathrm{PF}$ & $\mathrm{FP}$ & LO & $\mathrm{RP}$ \\
\hline \multirow[t]{2}{*}{$\mathrm{CS}^{*}$} & $w_{1}$ & 0.248 & 0.097 & 0.067 & 0.185 & 0.040 & 0.101 & 0.010 & 0.107 & 0.029 & 0.016 & 0.101 \\
\hline & Ranking & & & $B(C$ & $.765) \succ$ & $D(0.69$ & 9) $\succ A$ & $0.545)$ & $\succ C(0$. & 49) & & \\
\hline \multirow[t]{2}{*}{1} & $w_{2}$ & 0.097 & 0.248 & 0.067 & 0.185 & 0.040 & 0.101 & 0.010 & 0.107 & 0.029 & 0.016 & 0.101 \\
\hline & Ranking & & & $D($ & $.756) \succ$ & $B(0.75$ & 0) $\succ A$ & $(0.526)$ & $\succ C(0$. & 49) & & \\
\hline \multirow[t]{2}{*}{2} & $w_{3}$ & 0.067 & 0.097 & 0.248 & 0.185 & 0.040 & 0.101 & 0.010 & 0.107 & 0.029 & 0.016 & 0.101 \\
\hline & Ranking & & & $B(0$ & $.772) \succ$ & $A(0.65$ & 2) $\succ D$ & $0.625)$ & $\succ C(0$. & 49) & & \\
\hline \multirow[t]{2}{*}{3} & $w_{4}$ & 0.185 & 0.097 & 0.067 & 0.248 & 0.040 & 0.101 & 0.010 & 0.107 & 0.029 & 0.016 & 0.101 \\
\hline & Ranking & & & $B(0$ & $.785) \succ$ & $A(0.66$ & 5) $\succ D$ & $(0.662)$ & $\succ C(0$. & 28) & & \\
\hline \multirow[t]{2}{*}{4} & $w_{5}$ & 0.040 & 0.097 & 0.067 & 0.185 & 0.248 & 0.101 & 0.010 & 0.107 & 0.029 & 0.016 & 0.101 \\
\hline & Ranking & & & $B(0$ & 637) $\succ$ & $A(0.46$ & 7) $\succ D$ & $0.455)$ & $\succ C(0$. & 44) & & \\
\hline \multirow[t]{2}{*}{5} & $\mathrm{w}_{\mathrm{i}}$ & 0.101 & 0.097 & 0.067 & 0.185 & 0.040 & 0.248 & 0.010 & 0.107 & 0.029 & 0.016 & 0.101 \\
\hline & Ranking & & & $B(0$ & $.794) \succ$ & $D(0.61$ & 3) $\succ A$ & $(0.461)$ & $\succ C(0$. & 63) & & \\
\hline \multirow[t]{2}{*}{6} & $w_{7}$ & 0.010 & 0.097 & 0.067 & 0.185 & 0.040 & 0.101 & 0.248 & 0.107 & 0.029 & 0.016 & 0.101 \\
\hline & Ranking & & & $B(0$ & $.774) \succ$ & $D(0.68$ & 7) $\succ A$ & $(0.584)$ & $\succ C(0$. & 49) & & \\
\hline \multirow[t]{2}{*}{7} & $w_{8}$ & 0.107 & 0.097 & 0.067 & 0.185 & 0.040 & 0.101 & 0.010 & 0.248 & 0.029 & 0.016 & 0.101 \\
\hline & Ranking & & & $B(0$ & $795) \succ$ & $D(0.62$ & 9) $\succ A$ & 0.498) & $\succ C(0$ & 49) & & \\
\hline \multirow[t]{2}{*}{8} & $w_{9}$ & 0.029 & 0.097 & 0.067 & 0.185 & 0.040 & 0.101 & 0.010 & 0.107 & 0.248 & 0.016 & 0.101 \\
\hline & Ranking & & & $A(\mathrm{C}$ & $.739) \succ$ & $B(0.63$ & 0) $\succ D$ & $(0.374)$ & $\succ C(0$. & 44) & & \\
\hline \multirow[t]{2}{*}{9} & $w_{10}$ & 0.016 & 0.097 & 0.067 & 0.185 & 0.040 & 0.101 & 0.010 & 0.107 & 0.029 & 0.248 & 0.101 \\
\hline & Ranking & & & $D($ & $.681) \succ$ & $B(0.63$ & 2) $\succ C$ & $0.500)$ & $\succ A(0$. & 47) & & \\
\hline \multirow[t]{2}{*}{10} & $w_{11}$ & 0.101 & 0.097 & 0.067 & 0.185 & 0.040 & 0.101 & 0.010 & 0.107 & 0.029 & 0.016 & 0.248 \\
\hline & Ranking & & & $B(0$ & $.823) \succ$ & $D(0.48$ & 0) $\succ A$ & $(0.371)$ & $\succ C(0$. & 99) & & \\
\hline
\end{tabular}

Note: ${ }^{\text {aThe }} A$ Ss of alternatives are reported in the parenthesis; ${ }^{*}$ Current situation.

In Figure 3, in the CS the provider $D$ is determined as the best alternative. While the priority weights are changing mutually, the $A S$ s of alternatives and the rankings are changing, too. 


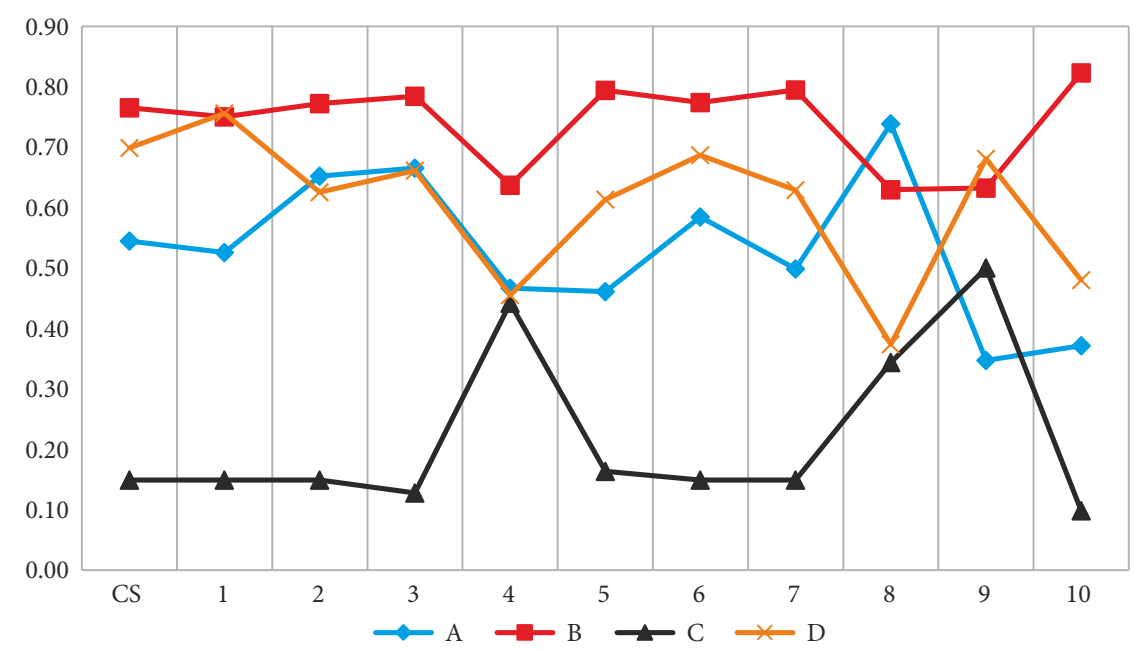

Fig. 3. The sensitivity analysis outcomes

In Case 1, if cost and relationship's priority weights are exchanged, then the AS of $D$ springs from 0.70 to 0.76 . Hence, the preference ranking of $D$ is changes from 2 to 1 . In Case 8, the $A S$ of $A$ springs from 0.54 to 0.74 when cost and financial position's priority weights are exchanged. It is the most conspicuous outcome of the sensitivity analysis. Nevertheless, $C$ usually has the lowest $A S$ when faced with the priority weight changes except Case 9. The highest ranking of $C$ is realized when the priority weights of cost and location are exchanged. B's maximum $A S$ is 0.82 by the exchange of priority weights of cost and relationship, that its ranking is 1 . Besides, $B$ is usually determined to be the most proper 3PLs provider in all tests with respect to the sensitivity analysis results since it has always maximum $A S$.

\section{Conclusions}

Selecting the suitable 3PLs provider is a difficult MCDM problem that includes both quantitative and qualitative criteria and is consistently associated with complexity and uncertainty. What is more in order to measure 3PLs provider performance, it is important to know how to measure it. This study, therefore, suggests a fuzzy integrated model which is capable of evaluating and selecting the best 3PLs provider by using two of the MCDM methods, namely the Fuzzy AHP and EDAS. First of all, the priority weights are determined based on Fuzzy AHP in this study. Next, the EDAS method which is relatively new MCDM method is used to prioritize and select the best 3PLs provider. In spite of working with a decision making team provides some advantages, it requires a coordinated act which can require great effort. Thereby, fuzzy numbers are utilized in AHP to avoid uncertainties in group decision making.

The applicability of this integrated model is proposed in a marble company for the evaluation of the 3PLs provider. Based on a review of existing literature, the present study 
take into accounts eleven 3PLs provider selection criteria, namely cost, relationship, services, quality, information system, flexibility, delivery, professionalism, financial position, location, and reputation. While collecting the responses of experts, the Delphi technique is conducted in pairwise comparisons. In all eleven selection criteria, the most important criterion for 3PLs provider selection is cost, followed closely by quality and professionalism in the present study. This suggests that whereas minimizing the total cost, maximizing the quality and professionalism are essentials of a successful outsourcing activity. However, these results do not necessarily suggest that less attention should be paid to other selection criteria. As a result of this study, the providers $B, D$, and $A$ are the top-three 3PLs providers and $D$, however, is the worst 3PLs provider. The case study validates that the proposed model is an effective and efficient decision making tool for the selection of a proper 3PLs provider. Additionally, a sensitivity analysis is performed to discuss and explain the proposed model results. It indicates that priority weights have an important role in the rank order of the alternatives.

Thus, this study's major contribution is to construct a framework, combining Fuzzy AHP with EDAS method, and use them for comprehensive evaluation of 3PLs provider based on the opinion of experts under fuzzy environments. The limitation of the proposed model is that number of criteria in a 3PLs provider selection problem, which make decision making more complicated. More clearly, the possibility of gaps in subjective judgments will increase if more criteria are included in the analysis. Although a 3PLs provider selection case is illustrated by the proposed model, it can be extended to other multicriteria logistics problems. For future research, this novel integrated fuzzy model can be successfully adapted to various FMCDM problems, such as financial problems, management problems, marketing problems, and so on.

\section{References}

Aghdaie, M. H.; Hashemkhani Zolfani, S.; Zavadskas, E. K. 2013. Market segment evaluation and selection based on application of fuzzy AHP and COPRAS-G methods, Journal of Business Economics and Management 14(1): 213-233 https://doi.org/10.3846/16111699.2012.721392

Aguezzoul, A. 2014. Third-party logistics selection problem: a literature review on criteria and methods, Omega 49: 69-78. https://doi.org/10.1016/j.omega.2014.05.009

Akman, G.; Baynal, K. 2014. Logistics service provider selection through an integrated fuzzy multicriteria decision making approach, Journal of Industrial Engineering 2014: 1-16. https://doi.org/10.1155/2014/794918

Alkhatib, S. F.; Darlington, R.; Yang, Z.; Nguyen, T. T. 2015. A novel technique for evaluating and selecting logistics service providers based on the logistics resource view, Expert Systems with Applications 42: 6976-6989. https://doi.org/10.1016/j.eswa.2015.05.010

Almeida, A. T. 2007. Multicriteria decision model for outsourcing contracts selection based on utility function and ELECTRE method, Computers and Operations Research 34(12): 3569-3574. https://doi.org/10.1016/j.cor.2006.01.003

Arslan, G.; Aydin, Ö. 2009. A new software development for fuzzy multicriteria decision-making, Technological and Economic Development of Economy 15(2): 197-212.

https://doi.org/10.3846/1392-8619.2009.15.197-212 
Balezentis, A.; Balezentis, T.; Misiunas, A. 2012. An integrated assessment of Lithuanian economic sectors based on financial ratios and fuzzy MCDM methods, Technological and Economic Development of Economy 18(1): 34-53. https://doi.org/10.3846/20294913.2012.656151

Balin, A.; Baraçli, H. 2015. A fuzzy multi-criteria decision making methodology based upon the interval type-2 fuzzy sets for evaluating renewable energy alternatives in Turkey, Technological and Economic Development of Economy (in press). https://doi.org/10.3846/20294913.2015.1056276

Banomyong, R.; Supatn, N. 2011. Selecting logistics providers in Thailand: a shippers' perspective, European Journal of Marketing 45(3): 419-437. https://doi.org/10.1108/03090561111107258

Bottani, E.; Rizzi, A. 2006. A fuzzy TOPSIS methodology to support outsourcing of logistics services, Supply Chain Management: an International Journal 11(4): 294-308. https://doi.org/10.1108/13598540610671743

Büyüközkan, G.; Feyzioğlu, O.; Nebol, E. 2008. Selection of the strategic alliance partner in logistics value chain, International Journal of Production Economics 113(1): 148-158. https://doi.org/10.1016/j.ijpe.2007.01.016

Chang, D. Y. 1992. Extent analysis and synthetic decision, Optimization Techniques and Applications 1(1): 352-355.

Chen, L. Y.; Wang, T. C. 2009. Optimizing partners' choice in IS/IT outsourcing projects: the strategic decision of fuzzy VIKOR, International Journal of Production Economics 120(1): 233-242. https://doi.org/10.1016/j.ijpe.2008.07.022

Cheng, A. C. 2013. A fuzzy multiple criteria comparison of technology valuation methods for the new materials development, Technological and Economic Development of Economy 19(3): 397-408. https://doi.org/10.3846/20294913.2013.821687

Chou, W. C.; Cheng, Y. P. 2012. A hybrid fuzzy MCDM approach for evaluating website quality of professional accounting firms, Expert Systems with Applications 39(3): 2783-2793. https://doi.org/10.1016/j.eswa.2011.08.138

Chow, H. K.; Choy, K. L.; Lee, W. B.; Chan, F. T. 2005. Design of a knowledge-based logistics strategy system, Expert Systems with Applications 29(2): 272-290. https://doi.org/10.1016/j.eswa.2005.04.001

Choy, K. L.; Chow, H. K.; Tan, K. H.; Chan, C. K.; Mok, E. C.; Wang, Q. 2008. Leveraging the supply chain flexibility of third party logistics-hybrid knowledge-based system approach, Expert Systems with Applications 35(4): 1998-2016. https://doi.org/10.1016/j.eswa.2007.08.084

Degraeve, Z.; Labro, E.; Roodhooft, F. 2004. Total cost of ownership purchasing of a service: the case of airline selection at Alcatel Bell, European Journal of Operational Research 156(1): 23-40. https://doi.org/10.1016/j.ejor.2003.08.002

Ecer, F. 2014. A hybrid banking websites quality evaluation model using AHP and COPRAS-G, Technological and Economic Development of Economy 20(4): 758-782. https://doi.org/10.3846/20294913.2014.915596

Ecer, F. 2015. Performance evaluation of internet banking branches via a hybrid MCDM model under fuzzy environment, Economic Computation and Economic Cybernetics Studies and Research 49(2): 211-230.

Efendigil, T.; Önüt, S.; Kongar, E. 2008. A holistic approach for selecting a third-party reverse logistics provider in the presence of vagueness, Computers and Industrial Engineering 54(2): 269-287. https://doi.org/10.1016/j.cie.2007.07.009

Falsini, D.; Fondi, F.; Schiraldi, M. M. 2012. A logistics provider evaluation and selection methodology based on AHP, DEA and linear programming integration, International Journal of Production Research 50(17): 4822-4829. https://doi.org/10.1080/00207543.2012.657969

Gao, L.; Hailu, A. 2013. Identifying preferred management options: an integrated agent-based recreational fishing simulation model with an AHP-TOPSIS evaluation method, Ecological Modelling 249: 75-83. https://doi.org/10.1016/j.ecolmodel.2012.07.002 
Gumus, A. T. 2009. Evaluation of hazardous waste transportation firms by using a two-step fuzzy-AHP and TOPSIS methodology, Expert Systems with Applications 36: 4067-4074.

https://doi.org/10.1016/j.eswa.2008.03.013

Hashemkhani Zolfani, S.; Sedaghat, M.; Zavadskas, E. K. 2012. Performance evaluating of rural ICT centers (telecenters), applying fuzzy AHP, SAW-G and TOPSIS Grey: a case study in Iran, Technological and Economic Development of Economy 18(2): 364-387.

https://doi.org/10.3846/20294913.2012.685110

Hsieh, T. Y.; Lu, S. T.; Tzeng, G. H. 2004. Fuzzy MCDM approach for planning and design tenders selection in public office buildings, International Journal of Project Management 22: 573-584.

https://doi.org/10.1016/j.ijproman.2004.01.002

Ho, W.; He, T.; Lee, C. K. M.; Emrouznejad, A. 2012. Strategic logistics outsourcing: an integrated QFD and fuzzy AHP approach, Expert Systems with Applications 39(12): 10841-10850. https://doi.org/10.1016/j.eswa.2012.03.009

Hsu, C. C.; Liou, J. J.; Chuang, Y. C. 2013. Integrating DANP and modified grey relation theory for the selection of an outsourcing provider, Expert Systems with Applications 40(6): 2297-2304. https://doi.org/10.1016/j.eswa.2012.10.040

Işıklar, G.; Alptekin, E.; Büyüközkan, G. 2007. Application of a hybrid intelligent decision support model in logistics outsourcing, Computers and Operations Research 34(12): 3701-3714. https://doi.org/10.1016/j.cor.2006.01.011

Jarzemskis, A. 2006. Determination and evaluation of the factors of outsourcing logistics, Transport 21(1): 44-47.

Jharkharia, S.; Shankar, R. 2007. Selection of logistics service provider: an analytic network process (ANP) approach, Omega 35(3): 274-289. https://doi.org/10.1016/j.omega.2005.06.005

Kabir, G. 2012. Third party logistic service provider selection using fuzzy AHP and TOPSIS method, International Journal for Quality Research 6(1): 71-79.

Kahraman, C.; Suder, A.; Kaya, I. 2014. Fuzzy multicriteria evaluation of health research investments, Technological and Economic Development of Economy 20(2): 210-226. https://doi.org/10.3846/20294913.2013.876560

Kannan, G.; Pokharel, S.; Kumar, P. S. 2009. A hybrid approach using ISM and fuzzy TOPSIS for the selection of reverse logistics provider, Resources, Conservation and Recycling 54(1): 28-36. https://doi.org/10.1016/j.resconrec.2009.06.004

Keshavarz Ghorabaee, M.; Zavadskas, E. K.; Olfat, L.; Turskis, Z. 2015. Multi-criteria inventory classification using a new method of evaluation based on distance from average solution (EDAS), Informatica 26(3): 435-451. https://doi.org/10.15388/Informatica.2015.57

Lehmusvaara, A.; Tuominen, M.; Korpela, J. 1999. An integrated approach for truck carrier selection, International Journal of Logistics Research and Applications 2(1): 5-20. https://doi.org/10.1080/13675569908901569

Liou, J. J.; Chuang, Y. T. 2010. Developing a hybrid multi-criteria model for selection of outsourcing providers, Expert Systems with Applications 37(5): 3755-3761. https://doi.org/10.1016/j.eswa.2009.11.048

Mardani, A.; Jusoh, A.; Zavadskas, E. K. 2015. Fuzzy multiple criteria decision-making techniques and applications - two decades review from 1994 to 2014, Expert Systems with Applications 42(8): 4126-4148. https://doi.org/10.1016/j.eswa.2015.01.003

Perçin, S.; Min, H. 2013. A hybrid quality function deployment and fuzzy decision-making methodology for the optimal selection of third-party logistics service providers, International Journal of Logistics Research and Applications 16(5): 380-397. https://doi.org/10.1080/13675567.2013.815696

Saaty, T. L. 1980. The Analytic Hierarchy Process. New York: McGraw Hill, 287 p. 
Safaei Ghadikolaei, A.; Khalili Esbouei, S.; Antucheviciene, J. 2014. Applying fuzzy MCDM for financial performance evaluation of Iranian companies, Technological and Economic Development of Economy 20(2): 274-291. https://doi.org/10.3846/20294913.2014.913274

Sharma, S. K.; Kumar, V. 2015. Optimal selection of third-party logistics service providers using quality function deployment and Taguchi loss function, Benchmarking: An International Journal 22(7): 1281-1300. https://doi.org/10.1108/BIJ-02-2014-0016

Thakkar, J.; Deshmukh, S. G.; Gupta, A. D.; Shankar, R. 2005. Selection of third-party logistics (3PL): a hybrid approach using interpretive structural modeling (ISM) and analytic network process (ANP), Supply Chain Forum: An International Journal 6(1): 32-46.

Vasiliauskas, A. V.; Jakubauskas, G. 2007. Principle and benefits of third party logistics approach when managing logistics supply chain, Transport 22(2): 68-72.

World Bank. 2015 [online], [cited 11 November 2015]. Available from Internet: http://lpi.worldbank. org/international/global/2014

Yayla, A. Y.; Oztekin, A.; Gümüş, A. T.; Gunasekaran, A. 2015. A hybrid data analytic methodology for 3PL transportation provider evaluation using fuzzy multi-criteria decision making, International Journal of Production Research 53(20): 6097-6113. https://doi.org/10.1080/00207543.2015.1022266

Zadeh, L. A. 1965. Fuzzy set, Information Control 18(2): 338-353. https://doi.org/10.1016/S0019-9958(65)90241-X

Zhang, G.; Shang, J.; Li, W. 2012. An information granulation entropy-based model for third-party logistics providers evaluation, International Journal of Production Research 50(1): 177-190. https://doi.org/10.1080/00207543.2011.571453

Zhang, Y.; Zhang, R. 2010. Study on the third party logistics service providers' performance evaluation based on the weighted entropy and analysis process of grey relation, in Proceedings of the $17^{\text {th }}$ International Conference on Management Science and Engineering, 24-26 November 2010. IEEE, Melbourne, Australia, 582-587. https://doi.org/10.1109/ICMSE.2010.5719861

Fatih ECER. He is an Associate Professor. He received his undergraduate degree from Dokuz Eylül University, Turkey and his PhD from Afyon Kocatepe University, Turkey in 2007. He has been with Afyon Kocatepe University, Department of Business Administration and head of the Quantitative Methods Division. His major research interests are in Multiple Criteria Decision Making (MCDM), fuzzy logic, artificial neural networks, and data mining. 